\title{
INEFICACIA DE LA FUNCIÓN PREVENTIVA, PROTECTORA Y RESOCIALIZADORA DE LA PENA DE MULTA POR INCAPACIDAD ECONÓMICA DEL CONDENADO EN EL SISTEMA PENAL PERUANO EN EL AÑO 2015
}

\author{
INEFFECTIVENESS OF THE PREVENTIVE, PROTECTIVE AND \\ RESOCIALIZING FUNCTION OF THE FINE PENALTY FOR ECONOMIC \\ DISABILITY OF THE CONDEMNED PERSON IN THE PERUVIAN CRIMINAL \\ SYSTEM IN 2015
}

JORGE ALBERTO DE AMAT PERALTA 1

\section{Resumen}

Se analiza de los diversos procesos penales en donde se han impuesto como pena la multa y su eficacia o no en su ejecución en el ámbito del Perú, así como un análisis doctrinario bibliográfico de las legislaciones extranjeras (Doctrina extranjera sobre la función de la pena de multa) en los países de España, Argentina e Italia. Se pretendió conocer el factor que determinaría el alto grado de ineficacia, así como identificar en qué sistemas jurídicos extranjeros resultaría fundamental y eficaz la pena de multa en su mecanismo de ejecución. La presente investigación se encuentra en el campo de jurídico-propositiva, de tipo aplicativo, socio jurídica. Se aplicó la técnica de la encuesta, la Técnica de Observación o Investigación Documental y análisis comparativo de doctrina extranjera. La población de estudio fueron jueces, fiscales en materia penal en un número de 100 y abogados también en número de 100 , de la ciudad de Tacna. Se ha precisado que el factor económico es el que determina el alto grado de ineficacia de la ejecución de la pena de multa en el sistema jurídico penal peruano y ha sido declarada prescrita por su incumplimiento por el transcurso del tiempo. Luego de haber verificado los resultados de la Doctrina especializada de los sistemas jurídicos de España, Argentina e Italia, pudiendo afirmar que la ineficacia de la función preventiva, protectora y resocializadora de la pena de multa en el Perú se debe a la capacidad económica (factor económico) del sujeto activo. Palabras Clave: multa, incapacidad económica.

\section{Abstract}

It is analyzed the various criminal processes where the fine and its effectiveness have been imposed or not in its execution in the field of Peru, as well as a bibliographic doctrinal analysis of the foreign legislations (Foreign doctrine on the function of the penalty of fine) in the countries of Spain, Argentina and Italy. It was intended to know the factor that would determine the high degree of ineffectiveness, as well as identify in which foreign legal systems would be fundamental and effective the penalty of fine in its enforcement mechanism. The present investigation is in the field of legal-propositive, of application type, legal partner. The technique of the survey, the Technique of Observation or Documentary Investigation and comparative analysis of foreign doctrine was applied. The study population were judges, prosecutors in criminal matters in a number of 100 and lawyers also in number of 100 , in the city of Tacna. It has been specified that the economic factor is what determines the high degree of ineffectiveness of the execution of the fine in the Peruvian criminal justice system and has been declared prescribed for its non-compliance over time. After having verified the results of the specialized doctrine of the legal systems of Spain, Argentina and Italy, I can affirm that the ineffectiveness of the preventive, protective and re-socializing function of the fine in Peru is due to the economic capacity (factor economic) of the active subject. Keywords: fine, economic incapacity. 
INTRODUCCIÓN

Muchos delitos son sancionados con pena de multa (pena conminada principal), así como también existen diversas faltas en el libro tercero del Código Penal que son conminadas con dicha sanción. Como puede verse en la ejecución de la sanción y cuando se emplaza al condenado a efectos que cumpla con el pago económico fijado como multa dentro del plazo de 10 días que establece el Código Penal encontramos que esta no se cumple y por tanto deviene ineficaz por diversos factores entre ellos el socioeconómico. Se puede afirmar que si una institución penal, como la pena de multa, no surte sus efectos sociales, esta deviene obsoleta; por lo tanto debe procederse a derogarse o modificarse dicha legislación con la finalidad de lograr que la respuesta punitiva del Estado cumpla la finalidad de la pena, y que dicha figura jurídica resulte inaplicable en el tiempo. En este sentido la capacidad económica del sujeto activo del delito es la condición principal de la ineficacia de la función preventiva, protectora y resocializadora de la pena de multa en los procesos penales en el sistema jurídico penal peruano en el año 2015, en relación al sistema jurídico de España, Italia y Argentina.

El problema radica en que en nuestra realidad contemporánea la pena de multa prevista en los artículos 28 y 41 y demás del Código Penal peruano resulta ineficaz (se impone judicialmente por mandato de la Ley, empero no se cristaliza su finalidad concreta); por tanto no se cumple con la función preventiva, protectora y socializadora que la legislación ha previsto en el artículo IX del Título Preliminar del Código Penal(1). Muchos delitos son sancionados con pena de multa (pena conminada principal) así como también existen diversas Faltas en el libro tercero del Código Penal que contemplan dicho tipo de respuesta punitiva. Como puede verse en la ejecución de la sanción y cuando se emplaza al condenado a efectos que cumpla con el pago económico fijado como multa dentro del plazo de 10 días que establece el Código Penal, encontramos que esta no se satisface, no se acata y por tanto deviene ineficaz por diversos factores, entre ellos el socioeconómicos y culturales (los ciudadanos condenados carecen de economía suficiente para solventar dicha imposición y culturalmente han asumido que los mandatos judiciales de esa naturaleza pueden desobedecerse sin consecuencias adversas).Se podrá verificar que las penas de multa no se ejecutan, es decir, los condenados a su pago, en su gran mayoría no abonan dicho concepto; lo cual constituye un latente y flagrante problema para la vigencia y aplicación del Derecho Penal.

En el caso de personas (condenadas) solventes, si la multa no es cancelada por mala voluntad dentro de los diez días o, establecida otra forma de pago, frustra su cancelación, el juez puede ejecutar la multa en los bienes del condenado solvente o convertirla en pena privativa de libertad. Teniendo en cuenta la finalidad perseguida con el sistema adoptado, solo deberá procederse a la conversión de la multa en pena privativa de libertad cuando la realización en los bienes del condenado sea infructuosa(2).

Tratándose de sentenciados insolventes, su situación frente a la ordenanza judicial no ha sido claramente regulada en el Código Penal, a diferencia del derogado. La interpretación más conveniente y coherente con el sistema escogido es la de comprender que la Ley se refiere más bien al procesado, quien previendo una condena a pena de multa puede voluntariamente colocarse en insolvencia. Si obra de esta manera (generando su incapacidad económica), debe convertirse la multa en pena privativa de libertad. Del mismo modo debe procederse contra el solvente que deliberadamente se resiste al pago de la multa. Pero si no es así, debe aplicarse una de las penas limitativas de derechos previstas como sanciones substitutas, toda vez que por principio general del Derecho a lo imposible nadie está obligado (no podría interpelarse racionalmente- el pago de multa imposible de pagar)(3). Pérez Castañeda(4) en su tesis señala que el sistema de días multa es aceptable; con la pena de multa se evita cualquier efecto transpersonal de la pena pues no afecta los ingresos para la manutención personal y familiar; no existen reglas para individualizar la pena de multa para quienes no tengan renta; no existe regulación para los casos de no cumplimiento de la prestación de servicios a la comunidad y pago fraccionado. Ponte Durango(5) refiere que La historia muestra que la pena de multa se ha venido aplicando desde hace muchos años atrás y por la gran mayoría de culturas precesoras a la nuestra, siendo que esta cobra gran arraigo por ser más efectiva que la pena privativa de la libertad de corta duración. En ese sentido, se tiene que la escasa inclinación de los jueces nacionales a aplicar la pena de multa se debe al sumo entender que dicha sanción no tiene el arraigo ni la fuerza coercitiva que tiene la pena 
privativa de la libertad, asimismo porque ella es de naturaleza leve. Prado Saldarriaga(6) afirma que la pena en el Peru ha cumplido y cumple una función de autoconstatación de un estado autoritario y represivo que antepone razones de estabilidad política a los mandatos y propósitos constitucionales, por lo expuesto estamos convencidos de que los artículos como el I y IX del título preliminar están de más en un sistema penal como el peruano y encierran de momento más hipocresía que buenas intenciones.

El Código Penal vigente desde 1991, implanta un sistema dual. Sin embargo, sobre cuál es la naturaleza de la pena o por qué o para qué se impone, es cuestión de amplios debates que se han dado a través de la historia del Derecho Penal. Así, la sanción nace debido a que, las relaciones entre los miembros de la sociedad no siempre son pacíficas; en toda sociedad existe la cuota de violencia entre los individuos que no pueden ser controladas con medios de control natural. Todo sistema social, incluso toda relación humana, requiere de instrumentos de control para evitar que los abusos de unos afecten o frustren las expectativas o los derechos de otros. El derecho penal moderno ha humanizado sus penas. En el Derecho Penal moderno existe una reserva del uso legítimo de la violencia en los poderes públicos, ya que el Estado es el único que utiliza las penas como un medio de control social legítimo. La pena, entonces, es el medio tradicional y más importante, dada su gravedad, de los que utiliza el Derecho.

La pena se justifica por su necesidad como medio de represión indispensable para mantener las condiciones de vida fundamentales para la convivencia de personas en una comunidad. Sin la pena, la convivencia humana en la sociedad actual sería imposible.

Desde los tiempos más remotos de nuestra historia, las sociedades, independientemente de la cultura de que se trate, han establecido un sistema de penas. Algunas con carácter de públicas u otras con el carácter de privadas; establecidas para lograr una venganza privada o bien para lograr una armónica convivencia de la sociedad (7). La PENA DE MULTA se define como una pena pecuniaria y consiste, como su nombre lo indica, en la disminución del patrimonio del penado mediante el pago de una suma de dinero exigida por ley a consecuencia de la comisión de un delito(8). A través de nuestra legislación penal la pena de multa presenta las siguientes características: Respecto al monto que se va a pagar a favor del Estado, la duración de la pena de multa fluctúa entre un mínimo de diez días a trescientos sesenticinco días multa, en virtud a lo dispuesto en el Artículo $42^{\circ}$ del Código Penal. La cuantía del día-multa es establecida en el Artículo $43^{\circ}$ del Código Penal, en el artículo $44^{\circ}$ del Código Penal, se determina la oportunidad de pago(9).

Uno de sus aspectos favorables es que socialmente mantiene al condenado como elemento activo ya que no se desperdicia su fuerza de trabajo; cuestión esta última que se materializa cuando a través de una sanción punitiva se le priva de su libertad ambulatoria. Se conserva al condenado en su medio sin destruir sus contactos familiares, laborales y sociales. No afecta el derecho al trabajo del condenado y no genera mayores costos para el Estado(9). Dentro de sus aspectos negativos implica una limitación en la calidad de vida del encartado, al afectar la capacidad su económica. La insolvencia del condenado puede llevar a la impunidad; reiteramos nuestra posición al respecto(9).

El principio de capacidad económica se ve como un principio con características propiamente jurídicas(10). La incorporación como norma en la Constitución, pues al estar consagrado en ella, se estimó que, indubitablemente, debía ser tratado como parte del Derecho vigente.

Desde el punto de vista del ideal de los valores jurídicos, la capacidad económica puede definirse como la riqueza disponible de un sujeto, y su contenido debiera exigir tres extremos: El principio del neto objetivo (estimación objetiva, capacidad objetiva), el principio del neto subjetivo (capacidad subjetiva) o de exoneración del mínimo existencial personal y familiar (de las personas físicas o naturales) y determinación de la intensidad del gravamen(10).

\section{OBJETIVOS CIENTÍFICOS}

a). Precisar cuál sería el factor que determinaría el alto grado de ineficacia de la pena de multa en los procesos penales en el sistema jurídico penal peruano en el año judicial 2015. b). Determinar en qué sistemas jurídicos extranjeros resultaría fundamental y eficaz la pena de multa en su mecanismo de ejecución. 


\section{METODOLOGÍA}

La presente investigación se enmarca dentro de la Tesis Jurídico-Propositiva. La forma de investigación es una investigación aplicada, tipo socio jurídica, cuasi experimental. La investigación se desarrolló en dos niveles, en primer lugar se realizó un análisis de los diversos procesos penales en donde se han impuesto como pena la multa en el ámbito del Perú, pero estadísticamente, asimismo, se aplicó una encuesta a los profesionales abogados y Magistrados de Tacna, para analizar la función de la pena de multa y su eficacia o no en su ejecución, y se presenta el sustento doctrinario y bibliográfico sobre la pena de multa; en segundo lugar se hizo un análisis doctrinario bibliográfico de las legislaciones extranjeras (Doctrina extranjera sobre la función de la pena de multa) en los países de España, Argentina e Italia. Se aplicó la técnica de la encuesta, la Técnica de Observación o Investigación Documental y análisis comparativo de doctrina extranjera y la técnica de investigación documental- expediente judicial - estadística. La población de estudio está representada por los jueces, fiscales en materia penal y abogados en número de 100, de la ciudad de Tacna.

Consiste en el registro de datos obtenidos por los instrumentos empleados en la recolección, mediante una técnica analítica en la cual se comprueba la hipótesis y se obtienen las conclusiones de la investigación.

\section{RESULTADOS}

Se analizaron 05 Ítems o preguntas. Respecto a la pregunta sobre a qué se debe la falta de ejecución de la pena de multa impuesta a un condenado, un $60 \%$ de la población encuestada considera que la falta de ejecución de la pena de multa se debe a los bajos ingresos económicos inferiores a una RMV, el $25 \%$ a pobreza y deficiente educación, el 5\% a falta de trabajo fijo. Respecto a qué factor cree que determina el alto grado de ineficacia de la pena de multa en los procesos penales, un $70 \%$ acusa que el factor económico determina el alto grado de ineficacia de la pena de multa, un $20 \%$ el factor socioeconómico y $10 \%$ el factor social. Según el reactivo si la pena de multa prevista en el Código Penal e impuesta a un condenado cumple la función preventiva y protectora de la pena hacia la sociedad, el $98 \%$ considera no cumple la función preventiva y protectora hacia la sociedad, y tan solo un $02 \%$ considera que sí. Respecto a si la pena de multa prevista en el Código Penal e impuesta a un condenado cumple la función resocializadora de este, un $99 \%$ considera que la pena de multa prevista en el Código Penal e impuesta a un condenado no cumple la función resocializadora, y tan solo un $01 \%$ considera que sí. A la cuestión de que alternativa propone al ser inejecutable por factores socioeconómicos, un $50 \%$ considera que debe de modificarse y aplicarse mecanismos de ejecución, un 38\% modificarse la pena de multa y aplicarse a ciertos delitos leves, un $10 \%$ considera que la pena de multa debe de derogarse del Código penal y un $02 \%$ considera que la multa prevista en el Código Penal no debe ser pena principal.

Según los resultados del análisis de las resoluciones de vista, se han emitido seis resoluciones de vista por la Sala Penal de la Corte Superior de Tacna, siendo las siguientes (Tabla 01) donde se puede advertir que la modalidad delictiva del tráfico ilícito de drogas informa que los agentes del delito (los condenados) son personas que por encontrarse en situación económica apremiante, fueron captados por los dueños de la droga para transportar dicha sustancia ilícita, siendo descubiertos antes de lograr su objetivo. En tal sentido, deducimos que por su estado de vulnerabilidad económica antes del delito, tampoco se encuentran en aptitud de abonar la pena de multa impuesta después de la comisión del delito (después de su condena).

Podemos colegir además, que de la revisión de las resoluciones de vista de los expedientes judiciales penales se aprecia que la ejecución de la pena de multa ha prescrito, por lo que la misma ha sido ineficaz. Vale decir, que según lo previsto por el artículo 80 del Código Penal la pena de multa prescribe a los dos años, y en los casos penales antes analizados la misma ha prescrito por el transcurso del tiempo y por ende a determinado su incumplimiento. Se ha verificado que el cumplimiento de la pena de multa no es eficaz y finalmente concluye en prescripción de la misma. 
Tabla 01: Resoluciones de vista

\begin{tabular}{|c|c|l|l|l|l|}
\hline$N^{\circ}$ & EXPEDIENTE & DELITO & $\begin{array}{l}\text { FECHA } \\
\text { RESOLUCIóN } \\
\text { DE VISTA }\end{array}$ & $\begin{array}{l}\text { RESOLUCIóN } \\
\text { DE VISTA: } \\
\text { DISPUSIERON }\end{array}$ & \\
\hline 1 & $1057-1997$ & $\begin{array}{c}\text { TID } \\
\text { AGRAVADO }\end{array}$ & $08 . J U N .16$ & $\begin{array}{l}\text { Prescripción De } \\
\text { La Pena De Multa }\end{array}$ & $\begin{array}{l}\text { Rehabilitar a } \\
\text { la sentenciada }\end{array}$ \\
\hline 2 & $557-2007$ & TID & 24. ICIC.15 & $\begin{array}{l}\text { Prescripción De } \\
\text { La Pena De Multa }\end{array}$ & $\begin{array}{l}\text { Rehabilitar al } \\
\text { sentenciado }\end{array}$ \\
\hline 3 & $1988-2007$ & TID & 10. DIC.15 & $\begin{array}{l}\text { Prescripción De } \\
\text { La Pena De Multa } \\
\text { E Inhabilitación }\end{array}$ & $\begin{array}{l}\text { Rehabilitar al } \\
\text { sentenciado }\end{array}$ \\
\hline 4 & $1618-2007$ & TID & 31. IC.15 & $\begin{array}{l}\text { Prescripción De } \\
\text { La Pena De Multa } \\
\text { E Inhabilitación }\end{array}$ & $\begin{array}{l}\text { Rehabilitar a } \\
\text { la sentenciada }\end{array}$ \\
\hline 5 & $814-2000$ & TID & 10. DIC.15 & $\begin{array}{l}\text { Prescripción De } \\
\text { La Pena De Multa } \\
\text { e Inhabilitación }\end{array}$ & $\begin{array}{l}\text { Rehabilitar al } \\
\text { sentenciado }\end{array}$ \\
\hline 6 & $136-1997$ & TID & 19. ENE.16 & $\begin{array}{l}\text { Prescripción De } \\
\text { La Pena De Multa } \\
\text { E Inhabilitación }\end{array}$ & $\begin{array}{l}\text { Rehabilitar al } \\
\text { sentenciado }\end{array}$ \\
\hline
\end{tabular}

\section{DISCUSIÓN}

De acuerdo a los resultados obtenidos se ha precisado que el factor económico es el que determina el alto grado de ineficacia de la ejecución de la pena de multa en el sistema jurídico penal peruano, asimismo, el análisis de las sentencias de vista de la Sala Penal de Tacna, comprueba que efectivamente la pena de multa impuesta ha sido declarada prescrita por su incumplimiento por el transcurso del tiempo. Asimismo, el factor económico es el que determina la ineficacia de la ejecución de la pena de multa; empero, del análisis de la doctrina y la legislación de los sistemas jurídicos de los países de España, Argentina e Italia se ha precisado que dichos modelos jurídicos son eficaces en la ejecución de la pena de multa.

Luego de haber verificado los resultados y concretado al revisión de las sentencias de la Sala Penal, de la Doctrina especializada del Perú y de la Doctrina especializada de los sistemas jurídicos de España, Argentina e Italia, podemos afirmar que realmente la ineficacia de la función preventiva, protectora y resocializadora de la pena de multa en el Perú se debe a la capacidad económica (factor económico) del sujeto activo, empero en los sistemas jurídicos analizados existen mecanismos de ejecución apropiados para el cumplimiento de la pena de multa.

\section{PROPUESTA LEGISLATIVA PROYECTO DE LEY}

\section{"LEY QUE MODIFICA LA PENA DE MULTA"}

ARTÍCULO 1.- Modifíquese el Artículo 41 del Decreto Legislativo $\mathrm{N}^{\circ} 635$, e incorpórese el Articulo 41-A,

Artículo 41.- La pena de multa obliga al condenado a pagar al Estado una suma de dinero fijada en díasmulta. El importe del día-multa es equivalente al ingreso promedio diario del condenado y se determina atendiendo a su patrimonio, rentas, remuneraciones, nivel de gasto y demás signos exteriores de riqueza, los mismos que deben de acreditarse a través de los mecanismos apropiados.

Extensión del Delito en la pena de multa

Artículo 41-A.- La pena de multa se aplicará exclusivamente a los delitos cuya pena a imponerse sea inferior a los cuatros años de pena privativa de libertad, y el juez de ejecución penal será el encargado de implementar los mecanismos y estrategias apropiadas para el pago total de la multa.

ARTÍCULO 2.- Reglamento.

Para el cumplimiento de la presente ley, reglaméntese la misma en el plazo 60 días.

ARTÍCULO3.- Vigencia.

La presente ley entrada en vigencia con la expedición de su reglamento.

\section{DISPOSICIÓN FINAL}

ARTÍCULO 4.-Deróguese o déjese sin efecto todas las disposiciones que se opongan a la Ley. 


\section{REFERENCIAS BIBLIOGRÁFICAS}

José Jayme Pérez Santa Cruz. Análisis y estudio de los beneficios penitenciarios en el Perú Monografias.com [Internet]. [citado 14 de noviembre de 2017]. Disponible en: http://www.monografias.com/trabajos 104/anal isis-y-estudio-beneficios-penitenciariosperu/analisis-y-estudio-beneficiospenitenciarios-peru.shtml2.

du Puit J. La pena de multa. Anu Derecho Penal. 1997;97:98.

Conversion de La Pena - Codigo Penal Peruano [Internet]. Scribd. [citado 14 de noviembre de

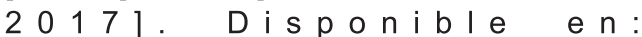
https://es.scribd.com/doc/187712856/Conver sion-de-La-Pena-Codigo-Penal-Peruano

Perez Castañeda J. La pena de multa en el Derecho penal peruano. Desarrollos normativos y jurisprudenciales [Internet]. 2005 . Dis pon ible en: http://cybertesis.unmsm.edu.pe/bitstream/cyb ertesis/2124/1/Perez_cj.pdf

CONCYTEC PERU. Repositorio ALICIA [Internet]. [citado 14 de noviembre de 2017]. Disponible en: http://alicia.concytec.gob.pe/vufind/

Saldarriaga VP. La función de la pena en el código penal de 1991. Derecho PUCP [Internet]. 1 de diciembre de 2013 [citado 14 de noviembre de 2017];0(46):101-12. Disponible en: http://revistas.pucp.edu.pe/index.php/derecho pucp/article/view/6176

Saenz Loayza C. Tesis de Doctorado en Derecho. Epistemología de la pena. Iquitos Peru. 2014. Pag. 20, 21, 22.

La Aplicación de La Pena de Multa Frente Al Sistema Punitivo Peruano - Documents [Internet]. documents.mx. [citado 14 de noviembre de 2017]. Disponible en: https://documents.mx/documents/laaplicacion-de-la-pena-de-multa-frente-alsistema-punitivo-peruano.html

Citado en http://pablolevano.org.pe/2016/02/05/laaplicacion-de-la-pena-de-multa-frente-alsistema-punitivo-peruano-alcances-ydificultades/.En.

- Masbernat Muñoz P. EL PRINCIPIO DE CAPACIDAD ECONÓMICA COMO PRINCIPIO JURÍDICO MATERIAL DE LA TRIBUTACIÓN: SU ELABORACIÓN DOCTRINAL Y JURISPRUDENCIAL EN ESPAÑA. Ius Prax [Internet]. 2010 [citado 14 de noviembre de 2017];16(1):303-32. D i s p n ible e n : http://www.scielo.cl/scielo.php?script=sci_abs $\mathrm{t} r$ a $c$ t \& $\mathrm{p}$ i $\mathrm{d}=\mathrm{s} \quad 0 \quad 7 \quad 1 \quad 8$ $00122010000100011 \&$ lng $=$ es \&nrm=iso\&tlng= es

Presentado: Marzo 2017

Aceptado: Junio 2017 